\title{
BMJ Economic crisis and smoking behaviour: Open prospective cohort study in Iceland
}

\author{
Christopher Bruce McClure, ${ }^{1,3}$ Unnur A Valdimarsdóttir, ${ }^{1}$ Arna Hauksdóttir, ${ }^{1}$ \\ Ichiro Kawachi
}

To cite: McClure $\mathrm{CB}$, Valdimarsdóttir UA, Hauksdóttir A, et al. Economic crisis and smoking behaviour: prospective cohort study in Iceland. BMJ Open 2012;2: 001386 .

doi:10.1136/bmjopen-2012001386

- Prepublication history and additional material for this paper are available online. To view these files please visit the journal online (http://dx.doi.org/10.1136/ bmjopen-2012-001386).

Received 26 April 2012 Accepted 6 September 2012

This final article is available for use under the terms of the Creative Commons Attribution Non-Commercial 2.0 Licence; see http://bmjopen.bmj.com

${ }^{1}$ Department of Medicine, Centre of Public Health Sciences, University of Iceland, Reykjavik, Iceland ${ }^{2}$ Department of Society, Human Development, and Health, Harvard School of Public Health, Boston, Massachusetts, USA ${ }^{3}$ College of Public Health and Human Sciences, Oregon State University, Corvallis, Oregon, USA

Correspondence to Christopher Bruce McClure; cbm1@hi.is

\section{ABSTRACT}

Objective: To examine the associations between the 2008 economic collapse in Iceland and smoking behaviour at the national and individual levels.

Design: A population-based, prospective cohort study based on a mail survey (Health and Wellbeing in Iceland) assessed in 2007 and 2009.

Setting: National mail survey.

Participants: Representative cohort $(n=3755)$ of Icelandic adults.

Main outcome measure: Smoking status.

Results: A significant reduction in the prevalence of smoking was observed from 2007 (pre-economic collapse) to 2009 (postcollapse) in both males (17.4-14.8\%; p 0.01) and females (20.0-17.5\%; $p$ $0.01)$ in the cohort $(n=3755)$. At the individual level of analysis, male former smokers experiencing a reduction in income during the same period were less likely to relapse (OR $0.37 ; 95 \% \mathrm{Cl} 0.16$ to 0.85 ). Female smokers were less likely to quit over time compared to males (OR $0.65 ; 95 \% \mathrm{Cl} 0.45$ to 0.93 ). Among male former smokers who experienced an increase in income between 2007 and 2009, we observed an elevated risk of smoking relapse (OR 4.02; 95\% Cl 1.15 to 14.00).

Conclusions: The national prevalence of smoking in Iceland declined following the 2008 economic crisis. This could be due to the procyclical relationship between macro-economic conditions and smoking behaviour (ie, hard times lead to less smoking because of lower affordability), or it may simply reflect a continuation of trends already in place prior to the crisis. In individual-level analysis, we find that former smokers who experienced a decline in income were less likely to relapse; and conversely, an increase in income raises the risk. However, caution is warranted since these findings are based on small numbers.

\section{INTRODUCTION}

The Icelandic economy was severely affected by the global economic collapse of 2008 . After a decade-long period of financial prosperity the nation was plunged into a recession of great severity, resulting in a severe currency crisis, as well as a drastic increase in

\section{ARTICLE SUMMARY}

Article focus

- An examination on the association between economic crises and smoking behaviours, that is, is change in income (at both the national and individual levels) related to a change in smoking status?

Key messages

- National smoking prevalence declined in Iceland following the 2008 economic crisis.

- In individual-level analysis, male former smokers whose incomes declined experienced a reduced risk of smoking relapse.

- Conversely, an increase in income from 2007 to 2009 was associated with increased risk of relapse.

- Our findings are consistent with the hypothesis that economic downturns may result in decreased tobacco use (procyclical effect).

Strengths and limitations of this study

- A representative prospective cohort study assessed at two time points, which straddle the start of a severe economic crisis.

- Owing to the low number of individuals that change their smoking behaviours in a short period, we were unable to assess the effects of a change in employment on smoking habits.

- Findings are based on a low number of subjects and must be taken with caution.

national and household debts, runaway unemployment rates and decreased per capita purchasing power. ${ }^{12}$

Previous research on the health consequences of the Icelandic economic collapse has suggested adverse impacts on cardiovascular and mental health among women. ${ }^{3} 4$ In the broader literature on economic crises and population health, however, it has been debated whether health moves in a procyclical or counter-cyclical direction to macroeconomic conditions. The work of Brenner ${ }^{5}$ beginning in the 1970s suggested that mortality is counter-cyclical, that is, when the economy is down, death rates-in particular, suicides-rise. However, in more recent 
years, a series of econometric studies have suggested that mortality is procyclical, that is, during economic contractions death rates decline. ${ }^{6-9}$ There are plausible reasons for this unexpected finding-for instance, during the 1998 Korean financial crisis, economic activity was so depressed that there was a detectable decline in traffic-related mortality. ${ }^{10}$ Others have speculatedwithout direct evidence-that people are more likely to be over-worked and 'stressed' during economic booms than during busts, having less time flexibility to engage in health promoting behaviours. ${ }^{11} 12$

Few studies, however, have used individual-level data to test the association between recession and health, especially smoking. Most of the evidence to date has been at the ecological level, though not all. ${ }^{13}$ For instance, Shaw et $a l^{14}$ found a direct association between economic hardship and a propensity to smoke. Using US data, $\mathrm{Ruhm}^{12}$ previously reported that economic recession was associated with a decline in the prevalence of cigarette smoking. A recent report from Gallus et $a l^{15}$ found that the recent economic contraction in Italy has given rise to an increase in the percentage of current smokers-primarily for women. In the present study, we took advantage of the natural experiment afforded by the Icelandic crisis to examine the relationship between changes in economic conditions and smoking behaviour. Utilising a prospective cohort of Icelandic adults assessed before (in 2007) and after the start of the collapse (in 2009), we sought to examine the risk of relapse among precollapse former smokers, as well as quitting behaviour among current smokers in terms of economic changes. Furthermore, because of the important role of perceived stress on smoking status, we sought to examine the potential influence of stress on the studied associations. ${ }^{1617}$

\section{METHODS}

\section{Design and samples}

\section{Cohort}

Our cohort is based on the Health and Wellbeing in Iceland health survey. Data were collected by a questionnaire in two waves: (1) from October to December of 2007 (10-12 months precollapse), then again (2) between November and December of 2009 (13-14 months postcollapse). The cohort was based on a stratified random sample of the Icelandic population $(n=9807)$, which was selected from 12 strata: consisting of two geographic regions further stratified by six age groups. Of the initial 9807, a total of 5918 responded to the initial 2007 assessment (response rate of 60.3\%), with 4092 responding again to the modified version of the survey in 2007 (response rate of $82.8 \%$ of those who responded to the precollapse baseline survey). Because of the importance of stress as a potential predictor of smoking behaviour, we excluded individuals who did not have complete responses to the Perceived Stress Scale (PSS-4) in both 2007 and 2009. This left a final analytical sample of

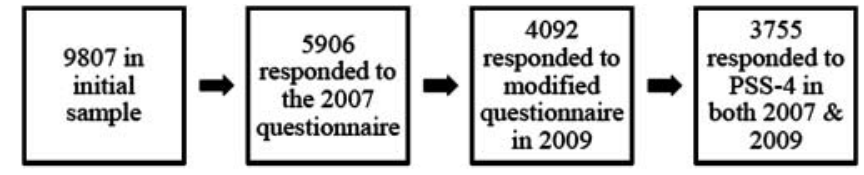

Figure 1 The cohort of the 'Health and well-being' study.

$\mathrm{n}=3755$. Figure 1 shows the cohort attrition over questionnaire waves.

\section{Measures}

Smoking status and behaviour

In the questionnaire, we inquired about smoking status, that is, whether respondents were current smokers, had quit smoking or had never smoked. In order to examine the likelihood of relapsing or quitting following an economic collapse, respondents were stratified according to their smoking status: non-smoker, relapsed and quit smoking.

Non-smoker: an individual was classified as a nonsmoker if they responded that they did not currently smoke on both the 2007 and 2009 assessments.

Relapsed smoker: an individual was identified as relapsed if they indicated that they (a) were a former smoker on the 2007 questionnaire, but indicated they had (b) smoked in any frequency in 2009. In our analyses estimating the ORs of relapse, the base population was restricted to individuals who were former smokers at baseline.

Quit smoking: a respondent who had quit smoking must have indicated that they were (a) currently smoking in 2007, yet had (b) quit smoking by 2009. In our analyses estimating the ORs of quitting, our base population was restricted to individuals who were current smokers at baseline.

\section{Change in economic status}

Additional socio-economic questions pertained to employment and income status. Household income was classified into income ranges of (in terms of Icelandic currency; ISK) (1) low ( $\leq 3.4$ million ISK), (2) middle (3.5-9.4 million ISK) and (3) high ( $\geq 9.5$ million ISK); corresponding approximately to (1) $\leq 28000$ US\$, (2) $28000-77000$ US $\$$ and (3) $\geq 77000$ US\$. For analysis of income change, household income was further dichotomised into either high or 'low' (which combined the middle-income and low-income categories). We examined two types of income change: (a) drop in income between 2007 and 2009 from high to low and (b) a rise in income between 2007 and 2009 from low to high.

\section{Change in perceived stress}

Psychological stress was measured in both 2007 and 2009 using the four-item PSS- $4 .{ }^{18}$ The PSS-4 is a shortened, validated and acceptable substitute for the original scale,${ }^{19}$ with scores ranging from 0 to 16 ; the higher the score, the higher the perceived stress. An increase in 
stress was classified as any increase from baseline to follow-up; conversely, a decrease was classified as any decrease from baseline to follow-up. For example, an individual with a score of 5 in 2007 and a score of 10 in 2009 would be classified as having an increase in stress.

\section{Explanatory variables and demographics}

Our regression models controlled for the following sociodemographic covariates: age, sex, marital status and education. Education was categorised as (1) basic (completed primary school or less), (2) middle (completed high school or equivalent) and (3) university (a completed university degree). Employment status was categorised as (1) employed, (2) unemployed, (3) student (4) homemaker/paternal leave, (5) retired and (6) disabled.

\section{Statistical analyses}

Table 1 presents the distribution of socio-demographic characteristics according to change in smoking status between 2007 and 2009.

Binary logistic regression was used to estimate OR (corresponding 95\% CIs) of relapse in 2009 (table 2), and the odds of quitting smoking in 2009 (table 3) by background characteristics, change in income and stress levels. Analyses were also stratified by gender. Models were adjusted for age and sex; models for household income and income change were additionally adjusted for baseline income levels. As previous research supports the role of stress as a mediator of an individual's propensity to change smoking status, ${ }^{15} 1620$ we also ran models of relapse and cessation with and without the inclusion of (1) changes in stress levels between 2007 and 2009 and (2) baseline stress levels.

Repeated measures analysis of variance ( $p$ values, $\mathrm{F}$ statistic) was used to examine overall and genderspecific mean differences in stress levels from 2007 to 2009 (table 4). Statistical analyses were conducted with IBM SPSS Statistics V.19.0 (SPSS Inc, Chicago, Illinois, USA). Statistical significance was set at the 0.05 level, and all tests were two-tailed.

\section{RESULTS}

\section{Baseline characteristics}

Table 1 describes the baseline characteristics of the cohort in $2007 \quad(\mathrm{n}=3755)$, which was $53.0 \%$ female, $76.7 \%$ married/cohabiting and with a mean (SD) age of 52.3 (16.0). Table 1 also describes the characteristics of those that had relapsed and quit: $72.2 \%(\mathrm{n}=2711)$ of the cohort were non-smokers, $4.0 \% \quad(n=56)$ of the former smokers at baseline had relapsed in 2009 and 22.2\% $(n=149)$ of smokers at baseline had quit smoking in 2009. A significant reduction $(p<0.01)$ in the prevalence of smokers was observed from 2007 to 2009 in both males (17.4-14.8\%) and females (20.0-17.5\%).

\section{Relapse smoking}

Among individuals who were former smokers at baseline (table 2), decreased odds of relapsing in 2009 (after the collapse) were observed in the older age groups

\begin{tabular}{|c|c|c|c|}
\hline & Cohort & Relapsed in 2009 & Quit smoking in 2009 \\
\hline $\mathrm{n}$ & 3755 & 56 & 160 \\
\hline Age mean $\pm S D$ & $52.3 \pm 16.0$ & $45.7 \pm 14.2$ & $47.4 \pm 15.5$ \\
\hline Sex & $\mathrm{n}(\%$ of category) & & \\
\hline Male & $1763(47.0)$ & $31(55.4)$ & $82(51.3)$ \\
\hline Female & $1992(53.0)$ & $25(44.6)$ & $78(48.8)$ \\
\hline \multicolumn{4}{|l|}{ Marital status } \\
\hline Single/divorced & 556 (14.9) & $7(13.0)$ & 31 (19.9) \\
\hline Committed, not cohabiting & $131(3.5)$ & $2(3.7)$ & $9(5.8)$ \\
\hline Married, cohabiting & $2871(76.7)$ & 45 (83.3) & $116(74.4)$ \\
\hline \multicolumn{4}{|l|}{ Education } \\
\hline Basic & $1688(47.1)$ & $22(40.7)$ & $65(42.5)$ \\
\hline Middle & $971(27.1)$ & $15(27.8)$ & $51(33.3)$ \\
\hline University & $928(25.9)$ & $17(31.5)$ & $37(24.2)$ \\
\hline \multicolumn{4}{|l|}{ Employment status } \\
\hline Employed & 2019 (58.4) & $37(71.2)$ & $98(64.5)$ \\
\hline Unemployed & $169(4.9)$ & $3(5.8)$ & $10(6.6)$ \\
\hline Student & $122(3.5)$ & $1(1.9)$ & $5(3.3)$ \\
\hline Homemaker/paternal leave & $159(4.6)$ & $2(3.8)$ & $9(5.9)$ \\
\hline Retired & $872(25.2)$ & $4(7.7)$ & $24(15.8)$ \\
\hline Disabled & 119 (3.4) & $5(9.6)$ & $6(3.9)$ \\
\hline \multicolumn{4}{|l|}{ Household income } \\
\hline Low & $621(20.6)$ & $8(17.0)$ & $22(16.5)$ \\
\hline Middle & $1855(61.4)$ & 25 (53.2) & $80(60.2)$ \\
\hline High & $543(18.0)$ & $14(29.8)$ & $31(23.3)$ \\
\hline
\end{tabular}


Table 2 The OR of relapsing in 2009 among those who had quit smoking at the baseline (2007)

\begin{tabular}{|c|c|c|c|c|}
\hline \multirow[b]{2}{*}{2009 status } & \multicolumn{4}{|c|}{ OR $(95 \% \mathrm{Cl})^{\star}$} \\
\hline & \multicolumn{2}{|c|}{ Overall } & \multirow[t]{2}{*}{$\begin{array}{l}\text { Male } \\
\text { Ref }\end{array}$} & $\begin{array}{l}\text { Female } \\
0.67(0.38 \text { to } 1.18)\end{array}$ \\
\hline Household income in 2009† & $\mathrm{n} \ddagger$ & & & \\
\hline Low & 8 & $0.66(0.26$ to 1.70$)$ & $1.13(0.24$ to 5.36$)$ & $0.56(0.15$ to 2.08$)$ \\
\hline Middle & 25 & $1.57(0.48$ to 5.17$)$ & $2.28(0.38$ to 13.55$)$ & $1.31(0.21$ to 8.32$)$ \\
\hline High & 17 & Ref & Ref & Ref \\
\hline \multicolumn{5}{|c|}{$\begin{array}{l}\text { Household income in } 2009 \text { (among high income at } \\
\text { baseline) } \dagger\end{array}$} \\
\hline High income in 2009 & 5 & Ref & Ref & Ref \\
\hline Lower income in 2009 & 9 & $0.53(0.28$ to 1.01$)$ & $0.37(0.16$ to 0.85$)$ & $0.92(0.29$ to 2.88$)$ \\
\hline \multicolumn{5}{|c|}{$\begin{array}{l}\text { Household income in } 2009 \text { (among low incomes at } \\
\text { baseline) } \dagger\end{array}$} \\
\hline High income in 2009 & 23 & 3.14 (1.27 to 7.72$)$ & $4.02(1.15$ to 14.00$)$ & 2.43 (0.64 to 9.19$)$ \\
\hline Lower income in 2009 & 7 & Ref & Ref & Ref \\
\hline \multicolumn{5}{|c|}{ Change in stress from 2007 to $2009 \S$} \\
\hline Same & 7 & Ref & Ref & Ref \\
\hline Decreased & 15 & 0.91 (0.35to 2.36) & 0.83 (0.23 to 2.99$)$ & $1.03(0.25$ to 4.28$)$ \\
\hline Increased & 34 & 1.71 (0.86 to 3.37$)$ & 1.75 (0.68 to 4.53$)$ & 1.64 (0.61 to 4.39$)$ \\
\hline
\end{tabular}

(compared to those aged 18-39), regardless of gender (age of 40-59: OR $0.38 ; 95 \%$ CI $0.21,0.69 \mid$ age $\geq 60$ : $0.10 ; 0.04,0.23)$.

While an individual's employment status was not involved in their risk of relapsing, retired women showed a significant increased risk of relapsing (4.12; $1.11,15.29)$, compared to the employed.
Among men in the lower-income groups at baseline (ie, low and middle), those who moved into the high-income group in 2009 experienced an increased risk of relapse (4.02; 1.15, 14.00)—while among those in the highincome group at baseline, those whose incomes dropped had a decreased risk of relapsing (0.37; 0.16, 0.85). Further adjustments for a change in stress levels from

Table 3 The OR of smoking cessation in 2009 among those who were smokers at the baseline (2007)

\begin{tabular}{|c|c|c|c|c|}
\hline \multirow[b]{2}{*}{2009 status } & \multicolumn{4}{|c|}{ OR $(95 \% \mathrm{Cl})^{\star}$} \\
\hline & \multicolumn{2}{|c|}{ Overall } & \multirow[t]{2}{*}{$\begin{array}{l}\text { Male } \\
\text { Ref }\end{array}$} & $\begin{array}{l}\text { Female } \\
0.65(0.45 \text { to } 0.93)\end{array}$ \\
\hline Household income in 2009† & $\mathrm{n} \ddagger$ & & & \\
\hline Low & 22 & $0.89(0.49$ to 1.60$)$ & $0.75(0.33$ to 1.74$)$ & $1.01(0.43$ to 2.36$)$ \\
\hline Middle & 80 & $0.98(0.45$ to 2.13$)$ & $0.80(0.27$ to 2.38$)$ & $1.12(0.36$ to 3.46$)$ \\
\hline High & 31 & Ref & Ref & Ref \\
\hline \multicolumn{5}{|c|}{$\begin{array}{l}\text { Household income in } 2009 \text { (among high income } \\
\text { at baseline)† }\end{array}$} \\
\hline High income in 2009 & 19 & Ref & Ref & Ref \\
\hline Lower income in 2009 & 6 & $0.75(0.46$ to 1.22$)$ & 0.82 (0.41to 1.62$)$ & 0.68 (0.34 to 1.37$)$ \\
\hline \multicolumn{5}{|c|}{$\begin{array}{l}\text { Household income in } 2009 \text { (among low incomes } \\
\text { at baseline) } \dagger\end{array}$} \\
\hline High income in 2009 & 85 & $0.68(0.30$ to 1.55$)$ & $0.61(0.19$ to 1.97$)$ & 0.77 (0.24 to 2.41$)$ \\
\hline Lower income in 2009 & 8 & Ref & Ref & Ref \\
\hline \multicolumn{5}{|c|}{ Change in stress from 2007 to $2009 \S$} \\
\hline Same & 22 & Ref & Ref & Ref \\
\hline Decreased & 62 & 0.84 (0.47 to1.48) & $0.73(0.34$ to 1.56$)$ & $0.98(0.41$ to 2.31$)$ \\
\hline Increased & 76 & 0.98 (0.64 to 1.51$)$ & 0.66 (0.36 to 1.22$)$ & 1.38 (0.74 to 2.58$)$ \\
\hline
\end{tabular}


Table 4 Average stress levels according to smoking status-among waves (2007 and 2009)

\begin{tabular}{lll}
$\begin{array}{l}2007 \\
\begin{array}{l}\text { Stress } \\
\text { mean (SD) }\end{array}\end{array}$ & $\begin{array}{l}\text { Stress } \\
\text { mean (SD) }\end{array}$ & p Value (F) \\
& & \\
$3.70(2.75)$ & $3.83(2.69)$ & $0.31(1.02)$ \\
$4.18(2.70)$ & $4.40(2.90)$ & $0.44(0.60)$ \\
& & \\
$3.52(2.28)$ & $4.94(2.80)$ & $0.28(1.20)$ \\
$3.96(2.52)$ & $5.24(3.46)$ & $0.01(7.67)$ \\
& & \\
$4.21(2.71)$ & $4.16(2.78)$ & $0.91(0.01)$ \\
$4.38(3.49)$ & $5.03(3.35)$ & $0.13(2.31)$ \\
\hline
\end{tabular}

${ }^{*}$ Repeated measures analysis of variance ( $p$ values, $F$ statistic) used to examine overall and gender-specific mean differences in stress levels from 2007 to 2009; adjusted for age in 2009.

2007 to 2009, showed limited attenuation in the coefficients, suggesting some mediation by perceived stressthat is, former smokers whose incomes increased between 2007 and 2009 may have relapsed in part because of an increase in stress.

\section{Smoking cessation}

Women were less likely to quit smoking in 2009 (0.65; $0.45,0.93)$, compared to men. An increased likelihood of quitting in 2009 was observed among the following female groups: those with middle $(2.78 ; 1.48,5.21)$ or university-level $(2.73 ; 1.38,5.40)$ education compared to a basic, and the disabled $(3.42 ; 1.23,9.52)$ compared to the employed. Compared to women aged 18-29, those in the middle-aged group $(0.46 ; 0.26,0.83)$ were less likely to quit. Additional adjustments for a change in stress levels from baseline to follow-up in the cessation models revealed no diminished significance in effect sizes.

\section{Stress and smoking}

Though stress change (increase versus Stable and decrease versus stable) did not predict a relapse in women in aforementioned analyses, further examination of changes in stress levels among smoking status displayed a significant change in mean stress levels (SD) among women that had relapsed, with a significant increase in stress scores from 3.96 (2.52) in 2007 to 5.24 (3.46) ( p 0.01; F=7.67).

\section{DISCUSSION}

In response to the severe economic collapse in Iceland, we found that the prevalence of smoking continued to decrease for both genders in the short period after. This drop in smoking may be attributed to background secular trends, ${ }^{21}$ while other factors, such as changes in the price of cigarettes, and changing norms about the acceptability of smoking, may also have played a role.
The strength of our study is that we were able to document changes in individual economic status straddling the economic downturn and link these exposures to individual changes in smoking habits. Additionally, in comparison to national smoking rates (2007: $23.0 \%$ of population; 2009: 19.0\%) the prevalence rates from 2007 to 2009 of this sample are relatively analogousoffering support for the generalisability of the sample.

Our findings partially corroborate previous research on the procyclical nature of the association between economic downturns and smoking habit, that is, during recessions, smoking habits may be dampened. Among male former smokers, those who experienced a decline in income during the economic recession had a significantly lower risk of relapse two years later. Conversely, among men whose incomes increased during the period of recession, their risk of relapse was considerably higher compared to those whose incomes stayed the same. Although the direction of associations was similar among women, none of the estimates were statistically significant.

Taken together, the main significant finding of our analyses is that male former smokers whose incomes fell during the period of the economic collapse experienced a reduced risk of relapse. $\mathrm{Ruhm}^{22}$ hypothesised that this risk reduction is possibly driven by a tendency to adopt healthier behaviours during periods of reduced income-driven by an increase in positive health behaviours (ie, exercise) that accompanies newly acquired increased leisure time during economic contractions. It could also be argued their behaviour change in a recession can be either intentional or inadvertent. When facing enforced economic inactivity-individuals may choose to fill their time by actively investing in positive personal health changes, which include stopping smoking or joining a fitness club. However, our results did not indicate an increased risk of quitting among those whose incomes fell-which is inconsistent with previous research by Siahpush and Carlin. ${ }^{23}$

It is possible that smoking cessation and smoking relapse are 'asymmetric' behaviours with different triggers. Thus, a former smoker who experiences a drop in income may be less tempted to start smoking again because of the reduced affordability of cigarettes. However, someone who is already smoking may be less sensitive to an income drop (higher income inelasticity) - that is, he is unable to quit his ongoing behavior because of the offsetting increase in stress (although our data on self-reported stress did not support this).

There is an apparent discrepancy between the national decline in smoking in Iceland and the fact that smokers whose incomes declined were not more likely to quit. This underscores the point that macrolevel data and individual-level patterns are often driven by a different set of causes. Thus, the overall decline in national smoking rates could be either due to the procyclical nature of smoking (ie, recessions are good for health), or it may simply reflect a continuation of trends already 
in place prior to the recession (ie, national antismoking campaigns, declining social acceptability of smoking, etc). In other words, national averages are driven by more than the group of smokers whose incomes decreased after the crisis.

Furthermore, we caution that our findings regarding recession, income change and smoking habits cannot be generalised to other health outcomes. For example, observational reports found a spike in female cardiac emergency visits during the week corresponding to the economic collapse in October 2008. ${ }^{3}$ In accordance with this, our previous analysis on changes in mental health revealed significant increases in stress for mainly women. ${ }^{4}$ This increase in stress for women, however, threatening to related health outcomes, did not prove to be associated with an increased likelihood of relapsing.

Our findings are also congruent with multiple models explaining the link between stress levels and smoking behaviour. Though much research shows stress as a cause of smoking, ${ }^{15} 16$ additional research actually points to cigarette smoking as a cause of stress and, furthermore, smoking cessation as leading to a reduction in stress. ${ }^{20}$ This is in line with our findings, as both male and female relapsed smokers had the lowest levels of stress before the collapse when they considered themselves as having quit smoking in 2007 (table 4), yet experienced an increase in stress postcollapse-significantly for women. This may also point to a vulnerability of this group to use smoking as a means of alleviating stress-explaining their relapse in smoking after the collapse. ${ }^{24}$ This vulnerability has been discussed and supported by previous research showing economic stress as a cause of adverse mental health. ${ }^{25}$ This increased stress may have also been amplified by a return to smoking, as Cohen and Lichtenstein ${ }^{26}$ have found. Caution is warranted in interpreting the findings on stress, however, since smokers may be citing an increase in perceived stress to justify their relapse or failure to quit. We cannot conclusively argue that stress did not play a mediating role in the association between income change and smoking behaviour because of measurement error.

\section{Study limitations}

Some limitations of our study should be noted. Relapsed smokers and quitters represent a small proportion of the population, and hence our ORs were estimated with imprecision and must be interpreted with caution. Similarly, we lacked statistical power to directly examine the effects of a change in employment status on change in smoking habits. In other words, though we were able to examine the effects of income change, we were not able to directly estimate the effects of unemployment as there were too few individuals in the sample who lost their jobs between 2007 and 2009. While our findings are based on the potential effects of an economic crisis on a change in smoking status, it is not clear whether these similar findings would hold true in normal scenarios and, thus, caution is warranted when generalising our findings to other normative scenarios. Finally, smoking status was based on self-report only, and not validated by biomarkers such as cotinine. This may have produced misclassification of the outcome, though it is not clear whether this misclassification was differential by exposure status (eg, income changes).

\section{Conclusions}

Our large population-based cohort with assessment points straddling the 2008 economic crisis in Iceland revealed a reduction in smoking rates from the short periods before and after the start of the crisis-though our study could not disentangle the direct effects of the crisis with other mechanisms, for example, secular trends and changing cigarette prices. Chiefly, this examination revealed a role of income change on the risk of relapse after the collapse among former male smokers.

Contributors CM and IK (study guarantor) were responsible for the design of the study and preparation of the manuscript. CM conducted data analyses. $\mathrm{AH}$ obtained funding. All contributors interpreted the data, contributed to the writing of the paper and approved the final version of the manuscript.

Funding The project was funded in part by the Icelandic Centre for Research (RANNÍS). The authors are responsible for the manuscript's content, not the funding bodies.

Competing interests None.

Ethics approval The study was approved by the Ethics Review Board of Iceland (09-094) and the Data Protection Authority of Iceland (S4455).

Provenance and peer review Not commissioned; externally peer reviewed.

Data sharing statement No additional data are available.

\section{REFERENCES}

1. Althingi. Special investigation report. Althingi (Icelandic Parliament) (Reykjavik, Iceland) http://sic (assessed 2 Aug 2012).

2. Statistics Iceland. Wages, income and labour market. Stat Ser 2010;996:391-28.

3. Gudjonsdottir GR, Kristjansson M, Olafsson O, et al. Immediate surge in female visits to the cardiac emergency department following the economic collapse in Iceland: an observational study. Emerg Med J 2012;29:694-8.

4. Hauksdóttir A, McClure C, Jónsson $\mathrm{SH}$, et al. Increased stress levels in women following an economic collapse. Am J Epidemiol. In press.

5. Brenner HM. Relation of economic change to Swedish health and social well-being, 1950-1980. Soc Sci Med 1987;25:183-95.

6. Tapias Granados JA. Increasing mortality during the expansions of the US economy, 1900-1996. Int J Epidemiol 2005;34:1194-202.

7. Tapias Granados JA. Macroeconomic fluctuations and mortality in postwar Japan. Demography 2008;45:323-43.

8. Tapias Granados JA, Diez Roux AV. Life and death during the great depression. Proc Natl Acad Sci USA 2009;106:17290-5.

9. Stuckler D, Basu S, Suhrcke M, et al. The public health effect of economic crises and alternative policy responses in Europe: an empirical analysis. Lancet 2009;374:315-23.

10. Khang Y-H, Lynch JW, Kaplan GA. Impact of economic crisis on cause-specific mortality in South Korea. Int J Epidemiol 2005;34:1291-301.

11. Ruhm CJ. Good times make you sick. J Health Econ 2003;22:637-58.

12. Ruhm CJ. Are recessions good for your health? Q J Econ 2000;115:617-50.

13. Shiahpush M, Carlin JB. Financial stress, smoking cessation and relapse: results from a prospective study of an Australian national sample. Addiction 2006;101:121-7.

14. Shaw B, Agahi N, Krause N. Are changes in financial strain associated with changes in alcohol use and smoking among older adults? J Stud Alcohol Drugs 2011;72:917-25. 
15. Gallus S, Tramacere I, Pacifici R, et al. Smoking in Italy 2008-2009: a rise in prevalence related to the economic crisis? Prev Med 2011;52:182-3.

16. Childs $\mathrm{E}$, de Wit $\mathrm{H}$. Effects of acute psychosocial stress on cigarette craving and smoking. Nicotine Tob Res 2010;12:449-53.

17. Tsourtos G, Ward PR, Muller R, et al. The importance of resilience and stress to maintaining smoking abstinence and cessation: a qualitative study in Australia with people diagnosed with depression. Health Soc Care Community 2011;19:299-306.

18. Cohen S, Kamarck T, Mermelstein R. A global measure of perceived stress. J Health Soc Behav 1983;24:385-96.

19. Cohen S, Williamson G. Perceived stress in a probability sample of the United States. In: Spacapam S, Oskamp S, eds. The social psychology of health: Claremont symposium on applied social psychology. Newbury Park, CA: Sage, 1988:31-67.
20. Parrott A. Does cigarette smoking cause stress? American Psychologist 1999;54:817-20.

21. Statistics Iceland. Lifestyle and health (Internet). http://www.statice. is/Statistics/Health,-social-affairs-and-justi/Lifestyle-and-health (accessed 20 April 2012)

22. Ruhm CJ. Healthy living in hard times. J Health Econ 2005;24:341-63.

23. Siahpush M, Carlin JB. Financial stress, smoking cessation and relapse: results from a prospective study of an Australian national sample. Addiction 2006;101:121-7.

24. Perkins KA, Grobe JE. Increased desire to smoke during acute stress. Br J Addict 1992;87:1037-40.

25. Aldwin CM, Revenson T. Vulnerability to economic stress. Am J Community Psychol 1986;14:161-75.

26. Cohen S, Lichtenstein E. Perceived stress, quitting smoking, and smoking relapse. Health Psychol 1990;9:466-78. 